
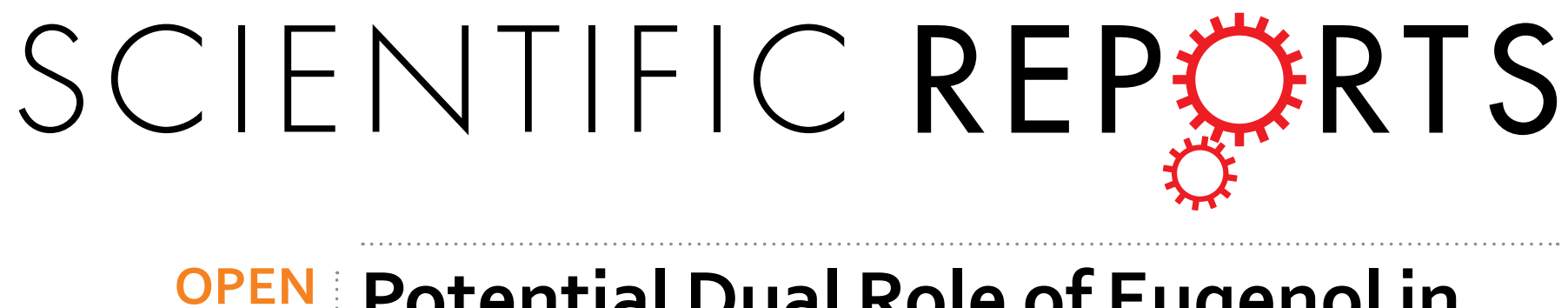

\title{
Potential Dual Role of Eugenol in Inhibiting Advanced Glycation End Products in Diabetes: Proteomic
}

Received: 29 May 2015

Accepted: 26 November 2015

Published: 07 January 2016

\section{and Mechanistic Insights}

Priyanka Singh ${ }^{1,2}$, Ramesha H. Jayaramaiah ${ }^{1}$, Sachin B. Agawane ${ }^{1}$, Garikapati Vannuruswamy ${ }^{1}$, Arvind M. Korwar ${ }^{1}$, Atul Anand ${ }^{1,2}$, Vitthal S. Dhaygude ${ }^{3}$, Mahemud L. Shaikh ${ }^{4}$, Rakesh S. Joshi ${ }^{5}$, Ramanamurthy Boppana ${ }^{4}$, Mahesh J. Kulkarni ${ }^{1}$, Hirekodathakallu V. Thulasiram ${ }^{2,6}$ \& Ashok P. Giri ${ }^{1}$

Medicinally important genus Ocimum harbors a vast pool of chemically diverse metabolites. Current study aims at identifying anti-diabetic candidate compounds from Ocimum species. Major metabolites in 0 . kilimandscharicum, 0 . tenuiflorum, 0. gratissimum were purified, characterized and evaluated for anti-glycation activity. In vitro inhibition of advanced glycation end products (AGEs) by eugenol was found to be highest. Preliminary biophysical analysis and blind docking studies to understand eugenol-albumin interaction indicated eugenol to possess strong binding affinity for surface exposed lysines. However, binding of eugenol to bovine serum albumin (BSA) did not result in significant change in secondary structure of protein. In vivo diabetic mice model studies with eugenol showed reduction in blood glucose levels by $38 \%$ likely due to inhibition of $\alpha$-glucosidase while insulin and glycated hemoglobin levels remain unchanged. Western blotting using anti-AGE antibody and mass spectrometry detected notably fewer AGE modified peptides upon eugenol treatment both in vivo and in vitro. Histopathological examination revealed comparatively lesser lesions in eugenol-treated mice. Thus, we propose eugenol has dual mode of action in combating diabetes; it lowers blood glucose by inhibiting $\alpha$-glucosidase and prevents AGE formation by binding to $\varepsilon$-amine group on lysine, protecting it from glycation, offering potential use in diabetic management.

Diabetes mellitus (DM) is a metabolic disorder of multiple etiologies characterized by elevated levels of blood glucose resulting from defects in insulin production, insulin action, or both. Pharmacological treatment of diabetes includes the use of oral anti-diabetic agents that aid in controlling hyperglycemia. These drugs either promote insulin secretion, insulin sensitivity; decrease the hepatic glucose output or aid in absorption of glucose. An important class of drug molecules, effective in management of diabetes is $\alpha$-glucosidase inhibitors. These regulate blood glucose level by inhibiting digestion of oligosaccharides/carbohydrates like maltose, maltotriose, dextrins, sucrose etc. into glucose ${ }^{1}$. Examples of $\alpha$-glucosidase inhibitors includes acarbose ${ }^{2}$, miglitol $^{3}$, voglibose ${ }^{4}$ etc. $^{2}$

Apart from these drugs, inhibition of advanced glycation end products (AGEs) is considered as a useful therapeutic strategy in management of diabetes. AGEs are formed by a series of non-enzymatic reactions between reducing sugars and amine group of proteins $s^{5,6}$. Upon glycation, proteins tend to lose their structure and function ${ }^{7}$. AGEs bind to receptor for AGEs (RAGE), spawn reactive oxygen species, and downstream signaling contributes basically in elicitation of pro-inflammatory response ${ }^{8}$.

AGEs and AGE-RAGE axis has been implicated in various disease pathophysiologies including vascular and diabetic complications ${ }^{5,6}$. Growing evidences on involvement of AGEs in disease has made them attractive

${ }^{1}$ Division of Biochemical Sciences, CSIR-National Chemical Laboratory, Pune 411008, Maharashtra, India. ${ }^{2}$ Division of Organic Chemistry, CSIR-National Chemical Laboratory, Pune 411008, Maharashtra, India. ${ }^{3}$ Krantisinh Nana Patil College of Veterinary Science, Shirwal, Satara 412 801, Maharashtra, India. ${ }^{4}$ National Centre for Cell Science, Pune 411007, Maharashtra, India. ${ }^{5}$ Institute of Bioinformatics and Biotechnology, Savitribai Phule Pune University, Pune 411007, Maharashtra, India. ${ }^{6}$ CSIR- Institute of Genomics and Integrative Biology, Mall Road, New Delhi 110007, India. Correspondence and requests for materials should be addressed to A.P.G. (email: ap.giri@ncl.res.in) 
therapeutic targets. Thus molecule(s) that inhibit the formation of AGEs are effective in management of diabetes. Consequently extensive research effort has been devoted to develop anti-AGE therapeutics. These includes (i) preventing the formation of AGEs, example, ascorbic acid ${ }^{9}$, aspirin ${ }^{10}$, metformin ${ }^{11}$, etc. (ii) de-glycation of Schiff bases/Amadori products involving transglycation approach using drugs like hydralazine ${ }^{12}$, (iii) reversal of AGE induced modifications like cross links, example, phenacylthiazolium bromide (PTB) ${ }^{13}$, and (iv) preventing the body from ill effects of AGE formation, example, resveratrol and curcumin ${ }^{14,15}$. Combination of oral drugs, and oral drugs with insulin has been used for better control of diabetes and diabetic vascular complications. For example, combination therapy with repaglinide and rosiglitazone has been verified to be safe and effective in diabetes treatment ${ }^{16}$. Similarly, combination of voglibiose with glibenclamide or gliclazide ${ }^{17}$; or miglitol with metformin ${ }^{18}$ offer better glycemic control.

Therapeutically important genus Ocimum, comprising herbaceous members belonging to family Lamiaceae, is considered a boon for medicinal chemists ${ }^{19}$. Leaf extracts of several species have a long and successful history of being used in ancient folk medicine; having antioxidant ${ }^{20}$, antistress ${ }^{21}$, anticancer ${ }^{22}$, radiation protection ${ }^{23}$, antifungal ${ }^{24}$, insecticidal ${ }^{25}$ and several other bioactivities. The key to this medicinal potential of genus Ocimum might lie in the vast array of secondary metabolites and phytochemicals including terpenoids, phenylpropanoids, flavonoids, phenolic compounds etc. present in various plant parts. Ocimum tenuiflorum (former O. sanctum) leaf extracts have been shown to have hypoglycemic effects by induction of insulin secretion from perfused pancreas, isolated islets and clonal pancreatic $\beta$-cells ${ }^{26,27}$; however, the principle compound and its mechanism of action are poorly understood. In view of this, we demonstrate the anti-diabetic activity of eugenol from $O$. gratissimum using in vitro and in vivo approaches. Here we have shown, eugenol isolated from O. gratissimum to have a potential dual effector role in diabetes control; it acts as an effective $\alpha$-glucosidase inhibitor as well as a glycation inhibitor, mimicking the effect of combination therapy. Although both synthetic and natural anti-diabetic therapeutics are available, latter seems to be the obvious choice owing to its low toxicity and lesser side effects. Thus, identifying anti-AGE lead molecules of natural origin would provide a significant thrust to diabetes research in future.

\section{Results and Discussion}

Chemical profiling unravels terpene and phenylpropanoid abundance in Ocimum species. GCMS based chemical profiling of leaf tissue of three Ocimum spp. revealed that each species was rich in a specific set of compounds representing a distinct metabolic fingerprint. Results indicated predominance of monoterpenes, sesquiterpenes and phenylpropanoids. Hydrocarbons including dodecane, dodecene, heptene, octane derivatives etc. were detected in minor quantities. The entire list of compounds identified is provided in Supplementary Table S1 online. Table 1 provides a selected subset of major metabolites screened for antiglycation activity using BSA-AGE assay.

In vitro inhibition of AGEs by metabolites from Ocimum species. Leaf and inflorescence extracts from three Ocimum species and major metabolites therein including camphor, eucalyptol, eugenol, eugenol methyl ether (EME), ocimene, $\alpha$-pinene, terpinolene, $\beta$-caryophyllene and farnesene were evaluated for their in vitro anti-glycation activity using BSA-AGE fluorescence assay. Maximum inhibition of glycation was observed with O. gratissimum extract, which is rich in eugenol. Inflorescence and leaf extracts of O. gratissimum inhibited the formation of AGEs by $74 \%$ and $72 \%$, respectively (Fig. 1a). O. tenuiflorum leaf extracts rich in EME showed least $(10 \%)$ inhibition of glycation (Fig. 1a). O. kilimandscharicum leaf and inflorescence extracts, rich in camphor and eucalyptol (Supplementary Table S1) displayed significant inhibition of AGE formation, $46 \%$ and $42 \%$, respectively (Fig. 1a). Of all the metabolites assessed, eugenol displayed highest, 58\% inhibition of glycation (Fig. 1b). Other metabolites did not inhibit AGE formation significantly. Based on these studies, eugenol, the major metabolite present in O. gratissimum was considered for in vivo studies. Inhibitory concentration required to inhibit $50 \%$ AGE formation $\left(\mathrm{IC}_{50}\right.$ ) for eugenol was $10 \mathrm{mM}$ (Fig. 2b) while for aminoguanidine hydrochloride was $1 \mathrm{mM}$ (Fig. 2a).

Since anti-glycation activity of extracts was significantly higher than that of individual metabolites, it was hypothesized that either of the following possibilities might exist: (i) anti-glycation activity of tissue extracts maybe due to synergistic action of a group of metabolites rather than a single metabolite or (ii) the metabolites present in planta are structurally modified, imparting them enhanced anti-glycation potential. To test this hypothesis, major metabolites (eugenol, EME and camphor) were purified and characterized by NMR analysis. Results indicated that there were no structural difference between metabolites present in planta, in comparison with standard compounds procured from Sigma-Aldrich (Supplementary Table S2). Since these metabolites present in planta were not structurally modified, it can be suggested that the increased antiglycation activity of Ocimum tissue extracts is probably due to synergistic effect of a group of metabolites. However, further investigation is required to acertain the hypothesis.

Eugenol shows increased binding affinity for surface lysine residues on mouse serum albumin but does not alter the protein secondary structure. Based on in vitro BSA-AGE assay, eugenol was observed to be a potent inhibitor of AGEs compared to EME. Structurally, the difference between eugenol and EME is that, in eugenol a hydroxyl group is present at the para position $\left(4^{\prime}-\mathrm{OH}\right)$; however, in EME this group is masked by the presence of a methyl group. We speculate the anti-glycation activity of eugenol might be due to the presence of free $4^{\prime}-\mathrm{OH}$ group. Previous studies support the fact that, presence and position of hydroxyl group determines the activity of flavonoids ${ }^{28}$. We imply that masking of active hydroxyl group in EME is responsible for decline in antiglycation activity of the compound. To gain more insight into eugenol-protein interaction, blind docking study of eugenol with mouse serum albumin (MSA) was performed. Out of many surface-exposed lysine, blind docking results indicate that eugenol preferentially binds to Lys-236 and Lys-375. In Fig. 3, surface exposed lysine residues have been marked in red, and binding of multiple eugenol molecules to single MSA molecule is depicted. Eugenol shows stronger binding (average binding energy, $6 \mathrm{Kcal} / \mathrm{mol}$ ) with surface exposed 


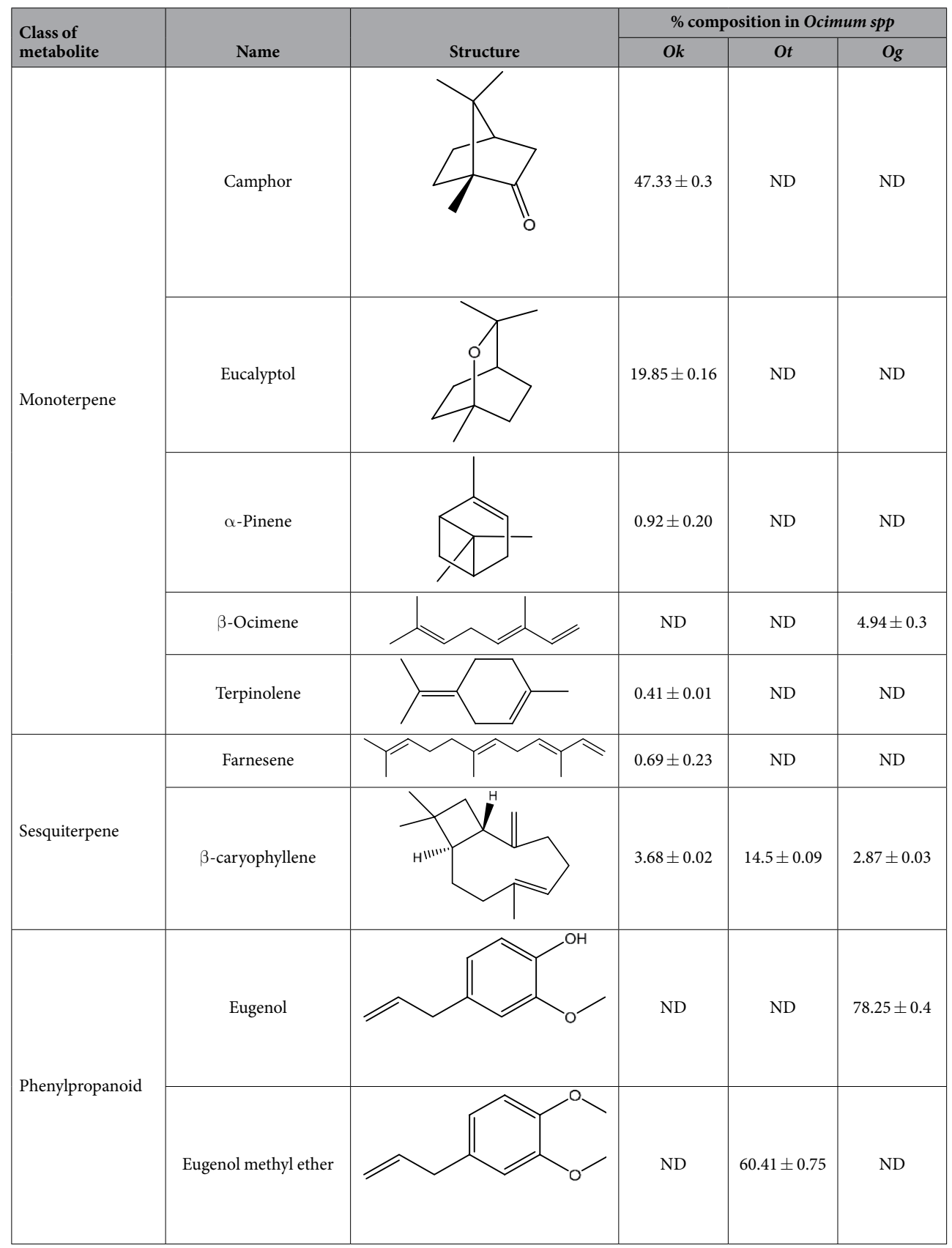

Table 1. Ocimum spp. metabolites screened for antiglycation activity using BSA-AGE assay. ^ND (not detected), Ok (O. kilimandscharicum), Ot (O. tenuiflorum), Og (O. gratissimum).

lysines as compared to aminoguanidine hydrochloride (average binding energy, $4.3 \mathrm{Kcal} / \mathrm{mol}$ ). EME also showed strong binding affinity for MSA (Supplementary Fig. S1), however, it did not display good inhibition of glycation in vitro. Thus, preliminary evidence suggests that the $4^{\prime}-\mathrm{OH}$ group of eugenol is potentially capable of binding to the amine group of lysine residues on protein molecule and competitively inhibiting the binding of sugar.

Intrinsic fluorescence assay and circular dichorism (CD) were performed to understand the nature of interaction between eugenol and BSA. In the intrinsic fluorescence assay, it was evident that eugenol binds to BSA in a concentration dependent manner (Fig. 4a). As the concentration of eugenol was increased, a consistent decrease in intrinsic fluorescence intensity was documented. CD of BSA incubated with eugenol was performed to understand the effect of binding of eugenol on the secondary structure of BSA. However, the secondary structure of BSA (Fig. 4b) remained unchanged $(84.3 \pm 1.9 \%$, $\alpha$-helix; $4.85 \pm 0.2 \%$, $\beta$-sheet; $4.45 \pm 1.9 \%$, $\beta$-turn; $7.4 \pm 0.2 \%$ unordered). The interaction did not induce any transition from $\alpha$-helix to $\beta$-sheet or vice versa. in the structure of protein. Hence we conclude that eugenol binds to BSA but the binding does not cause any significant change in the secondary structure of BSA. 
(a)

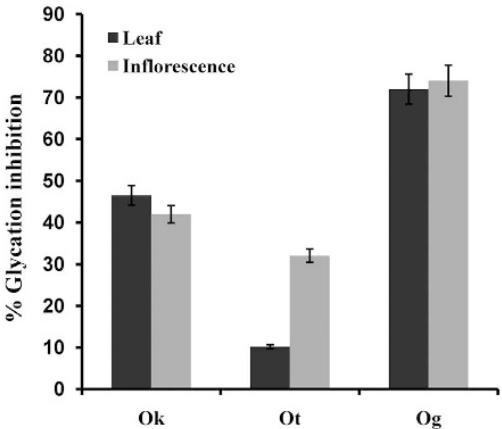

(b)

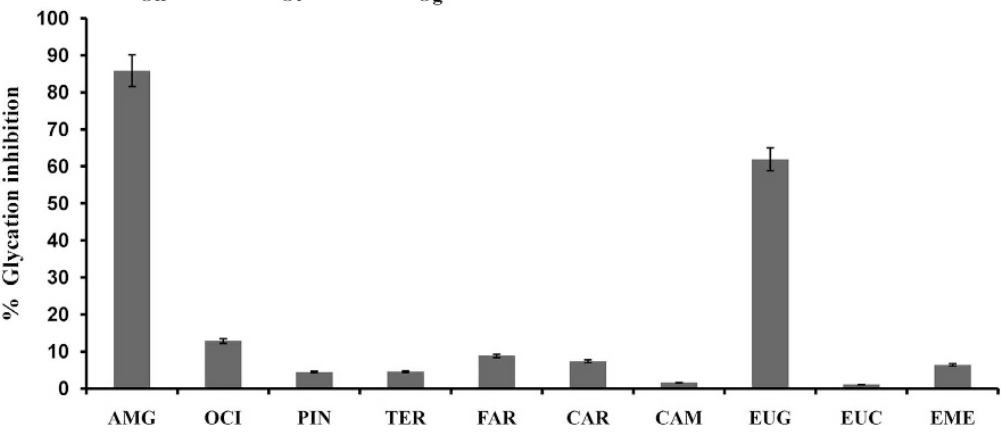

Figure 1. In vitro BSA-AGE inhibition assay. Glycation inhibition shown by (a) leaf and inflorescence extracts of $O$. kilimandscharicum (Ok), O. tenuiflorum $(\mathrm{Ot})$, O. gratissimum $(\mathrm{Og})$ and $(\mathbf{b})$ standard compounds, aminoguanidine (AMG), ocimene (OCI), pinene (PIN), terpinolene (TER), farnesene (FAR), $\beta$ - caryophyllene (CAR), camphor (CAM), eugenol (EUG), eucalyptol (EUC) and eugenol methyl ether (EME).

(a)

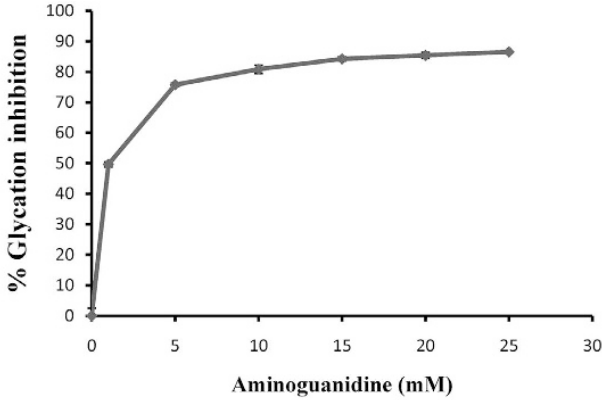

(b)

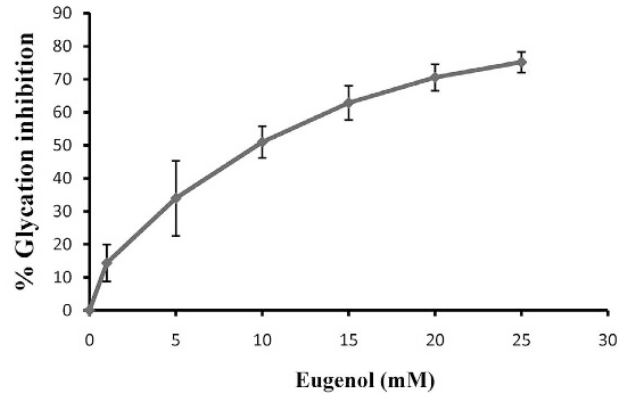

Figure 2. Glycation inhibition assays by aminoguanidine and eugenol. $\mathrm{IC}_{50}$ values for AGE inhibition by (a) Aminoguanidine and (b) Eugenol. Values represent mean \pm standard deviation $(\mathrm{n}=3)$.

Eugenol administration affects blood biochemical parameters. The effect of administration of eugenol on blood glucose, HbA1c and insulin was investigated. Since hyperglycemia is known to be the foremost cause of diabetic complications, molecule(s) that lower blood glucose are frontrunners for management of diabetes. Mice belonging to Group I (STZ control) and group II (vehicle control) did not show any significant decrease in blood glucose $(396 \mathrm{mg} / \mathrm{dL}$ and $353 \mathrm{mg} / \mathrm{dL}$, respectively). Mice belonging to Group III (eugenoltreated mice) exhibited a 38\% decrease in blood glucose, with levels dropping from $420 \mathrm{mg} / \mathrm{dL}$ to $262 \mathrm{mg} / \mathrm{dL}$, on an average (two-tailed p-value, 0.0042). Lowering blood glucose level helps subsequently in lowering formation of AGEs. Administration of eugenol showed significant decrease in blood glucose level (Fig. 5a). Although the 


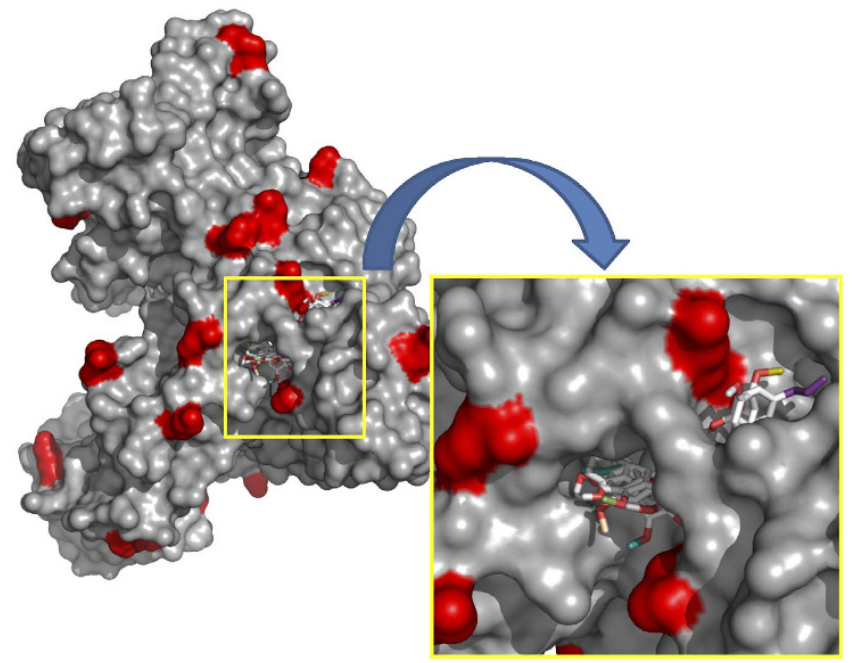

Figure 3. In silico analysis of interactions between eugenol and MSA. Blind docking and probablity analysis of eugenol with MSA. Surface exposed lysine have been marked in red. Inset depicts binding of several eugenol molecules to surface lysine residues on MSA.

(a)

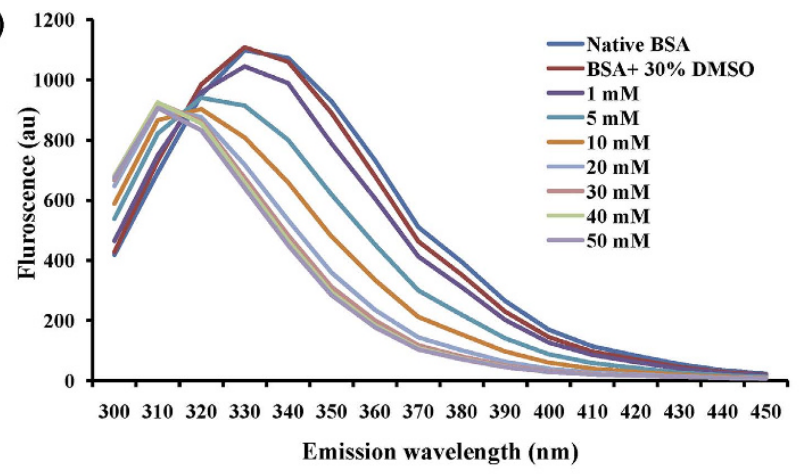

(b)

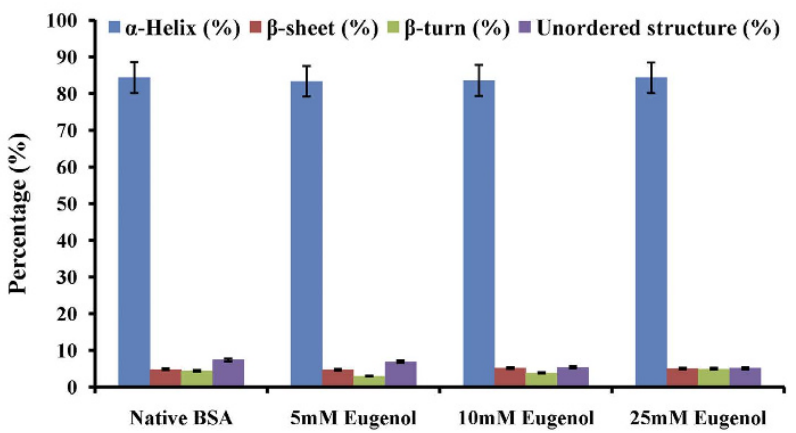

Figure 4. Biophysical analysis of BSA and eugenol interaction (a) Fluorescence quenching of BSA by eugenol (b) CDPro analysis of native BSA and BSA treated with 5, 10 and $25 \mathrm{mM}$ eugenol.

blood glucose levels decreased, it did not lead to a severe hypoglycemic condition. Decrease in blood glucose may be attributed to the inhibition of $\alpha$-glucosidase activity (Fig. 6), as discussed in subsequent section. Furthermore, the blood glucose levels increased when the treatment was withdrawn.

HbAlc essentially serves as a marker for monitoring glycemic status over a period of three months. We did not notice any significant change in HbA1c levels between different groups of mice: Group I (9.9), Group II (10.7), Group III (8.9), values in the parenthesis represent average for each group of treatment (Fig. 7a). The possible reason behind no significant change in HbAlc level may be due to the short duration of study (45 days). HbA1c levels are known to changes over a period of 3 to 4 months. Since our study was restricted to a short period of 45 days, no drastic changes in HbA1c levels were observed. No significant change in the insulin level was evident between the groups (Fig. 7b) suggesting that eugenol lowers the blood glucose by inhibiting glucosidase activity. 
(a)

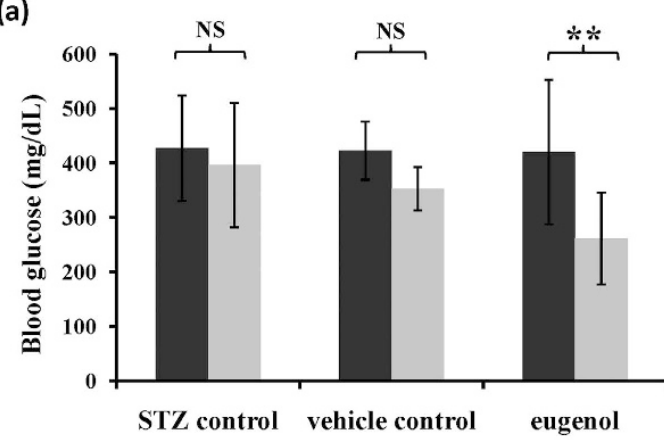

(c)

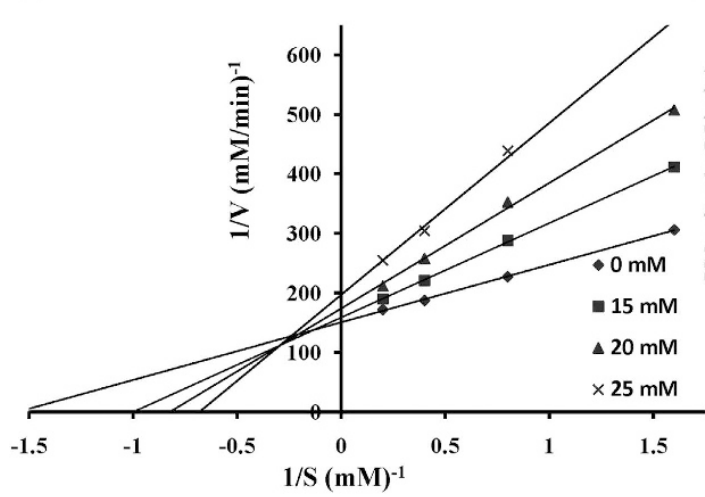

(b)

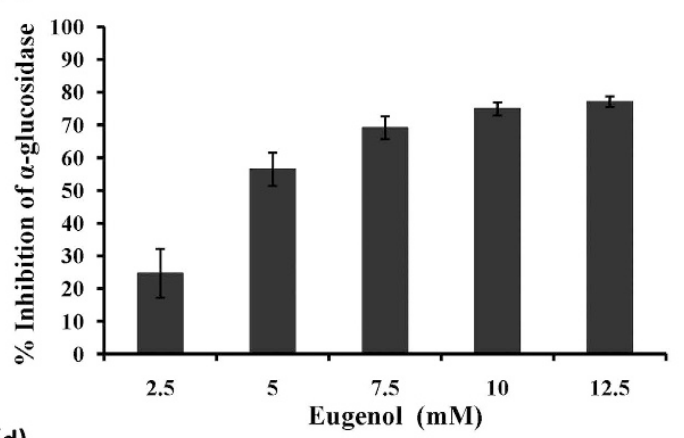

(d)

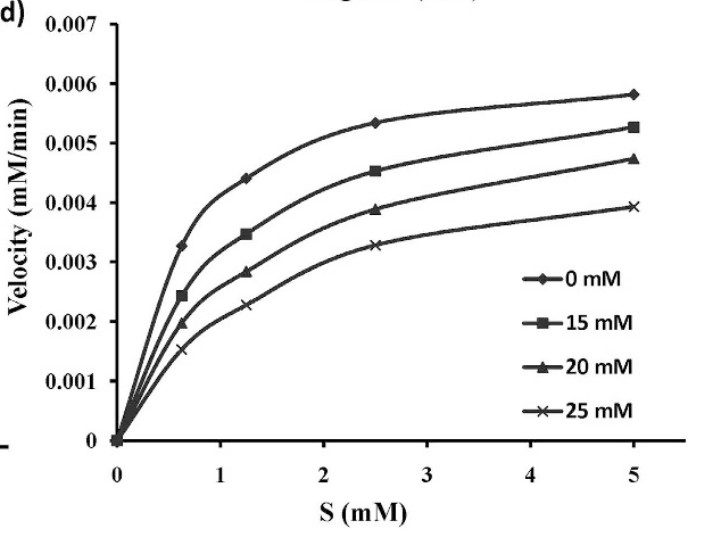

Figure 5. Kinetic studies of alpha-glucosidase inhibition by eugenol (a) Blood glucose measurement after intraperitoneal administration of eugenol $(n=8)$ in STZ- induced balb/c mice. Unpaired t-test suggested significant differences between data at $p<0.01$ (indicated as (**) ${ }^{(*)}$ and $p<0.05$ (indicated as (*)). NS represents nonsignificant difference in data. (b) $\alpha$-glucosidase inhibition assay. Inhibition kinetics depicted via (c) Lineweaverburke plot and (d) Michaelis- Menten plot showing mixed inhibition of $\alpha$-glucosidase by eugenol.

Mixed inhibition of $\alpha$-glucosidase by eugenol might lead to decrease in blood glucose. We speculate that, the decrease in blood glucose may be due to inhibition of intestinal $\alpha$-glucosidase. $\alpha$-Glucosidase is localized in brush border epithelium of small intestine and catalyzes the conversion of oligosaccharides/carbohydrates like maltose, maltotriose, dextrins, sucrose etc. into glucose. $\alpha$-Glucosidase inhibitors are known to lower blood glucose level by slowing carbohydrate metabolism ${ }^{2-4}$. Eugenol inhibited yeast $\alpha$-glucosidase in a concentration dependent manner (Fig. $5 \mathrm{~b}$ ) with $\mathrm{IC}_{50}$ value around $5 \mathrm{mM}$. Lineweaver-Burke plot analysis revealed mixed type of inhibition; thus, eugenol can bind to both enzyme and enzyme-substrate complex. Figure 6 shows a schematic representation of inhibition of $\alpha$-glucosidase by eugenol. Therefore, eugenol as an $\alpha$-glucosidase inhibitor can be a potential candidate in the treatment and management of diabetes.

Eugenol treated mice display significantly less histopathological lesions. Histopathology was performed to understand the gross and microscopic effect of eugenol on different tissues (spleen, liver, heart, lungs, kidney, pancreas and brain). Spleen, heart and lung tissues of mice belonging to all three groups did not show significant abnormal lesions. However, brain, pancreas, kidney and liver tissue displayed moderate to severe histopathological lesions depending upon the treatment administered. Mice belonging to Group I revealed most severe lesions (Fig. 8a) followed by those belonging to Group II (Fig. 8b). In both these groups, brain tissue revealed mononuclear cell proliferation and focal hemorrhages. Pancreas exhibited focal destruction of acinar cells, hemorrhages and mononuclear cell infiltration. Kidney sectioning exposed necrosis of tubular epithelial cells, focal hemorrhages and mononuclear cell infiltration. Liver reflected severe hemorrhages and focal necrosis of hepatic cells. Occurrence of these severe lesions may be due to oxidative stress related cell injury caused by hyperglycemia in these groups. Occurrence of aforementioned lesions was significantly less in mice belonging to Group III (Fig. 8c), however, mild degeneration was observed in hepatocytes. The results indicate that eugenol treated mice displayed healthier histopathology than diabetic mice emphasizing therapeutic effect of eugenol against hyperglycemia.

Western blot analysis shows in vitro and in vivo inhibition of AGEs by eugenol. Western blot analysis of in vitro BSA-AGE assay samples and in vivo plasma samples showed significant differences in eugenol-treated and un-treated glycated BSA (Fig. 9a,c) as well as eugenol-treated and un-treated STZ mice plasma (Fig. 9b,d) following statistical analysis of blot density data. The results clearly indicate significant reduction in binding of glucose in presence of eugenol, showing western blot relative density, 0.46 for eugenol-treated glycated BSA compared to control with $p=0.0008\left(p<0.001\right.$ indicated by $\left.{ }^{* *}\right)$ in BSA-AGE samples (Fig. 9c) and 0.64 for eugenol-treated STZ mice with $p=0.0011\left(p<0.01\right.$ indicated by $\left.{ }^{* *}\right)$ in in vivo plasma samples (Fig. 9d). 

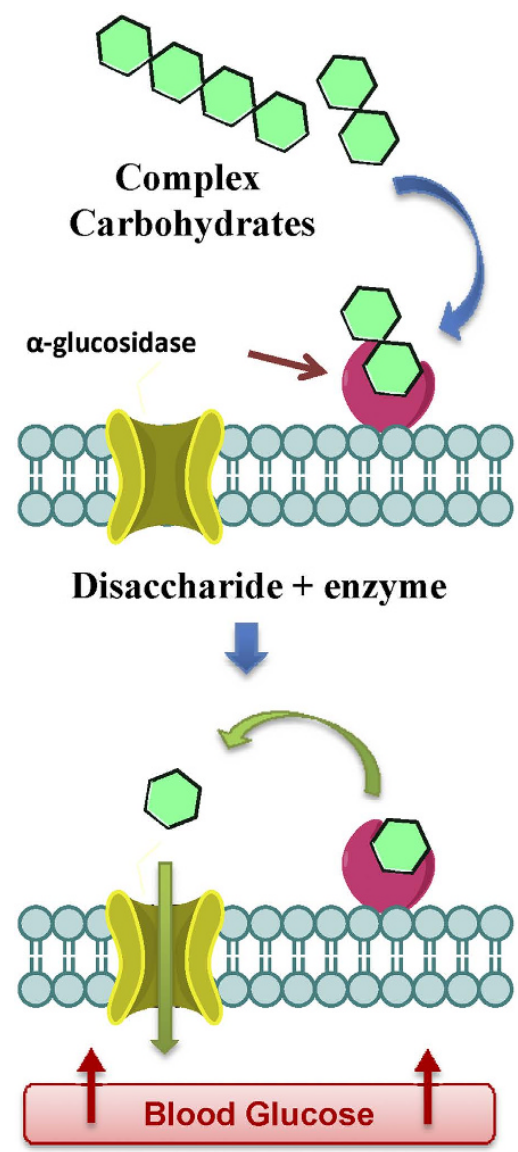

\section{Hydrolysis and absorption of Glucose}

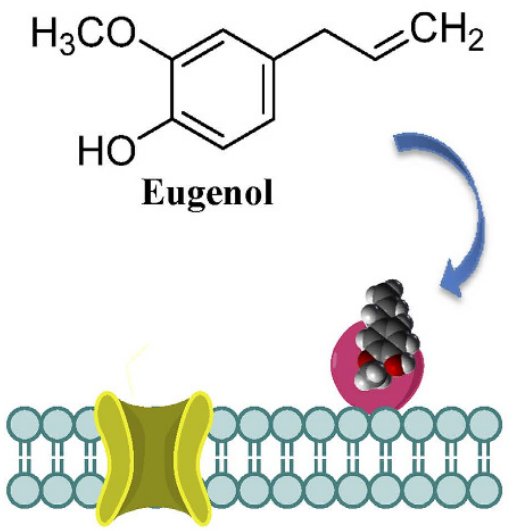

Inhibitor + enzyme
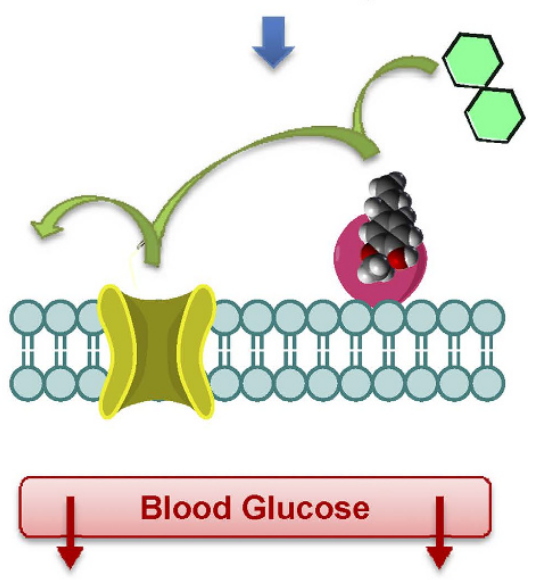

Inhibition of hydrolysis and absorption of Glucose

Figure 6. Inhibition of $\alpha$-glucosidase by eugenol slows carbohydrate metabolism resulting in decrease in blood glucose.

One of the reasons for lesser accumulation of AGEs in plasma could be because of decreased level of blood glucose, which can be attributed to $\alpha$-glucosidase inhibitory activity of eugenol. Further, eugenol can also inhibit the formation of AGEs by competitively inhibiting the binding of sugar to proteins both in vivo and in vitro, as discussed previously. Thus, both these factors result in overall lesser accumulation of AGEs.

LC-MS analysis reveals lesser extent of AGE modification on peptides upon eugenol treatment. LC-MS analysis was performed to understand the sites of AGE modification for both in vitro BSA-AGE assay and in vivo plasma protein especially mouse serum albumin (MSA). Heatmap analysis showing extent of AGE modification on glycated peptides, including glycation sensitive amino acid residues (GSAR) containing peptides of MSA is depicted in Fig. 9f. It was noticed that AGE modified peptides were found to decrease in response to eugenol treatment and were found to be highest in plasma of STZ treated diabetic mice. The MS/MS spectra of AGE modified peptides are provided in Supplementary Table S3 and Supplemetary Fig. S2. Glycation sensitive sites R168 and R452 $2^{12,29}$, which are suggested to be markers for type II diabetes ${ }^{29}$ significantly showed lesser extent of glycation in response to eugenol treatment. The fact that extent of AGE-modification is less on peptides containing GSAR residues, makes eugenol a convincing candidate for early inhibition of glycation. Similarly, eugenol showed significantly lesser AGE modification in in vitro glycated BSA sites K36, K88, K160, K184, K263, K438 and K548 in comparison with glycated BSA and positive control AMG (Fig. 9e). The MS/MS spectra for these sites are provided in Supplementary Table S4 and Supplementary Fig. S3). Thus, LC-MS analysis of glycated peptides reveals that eugenol, contributes significantly in reducing the extent of glycation, both in vitro and in vivo eventually resulting in lesser accumulation of AGEs.

\section{Conclusions}

We identified eugenol, a phenylpropanoid, as a potent inhibitor of AGEs both by in vitro and in vivo studies. We propose that eugenol exerts potential dual mode of action in combating AGEs (Fig. 10). It might inhibit intestinal $\alpha$-glucosidase and block the conversion of complex carbohydrates to glucose, resulting in lower blood glucose level and subsequent reduction in AGE formation. Also, eugenol competitively inhibits the binding of sugar to serum albumin by binding to amine group of surface exposed lysine residues via its reactive $4^{\prime}$-OH group. The 

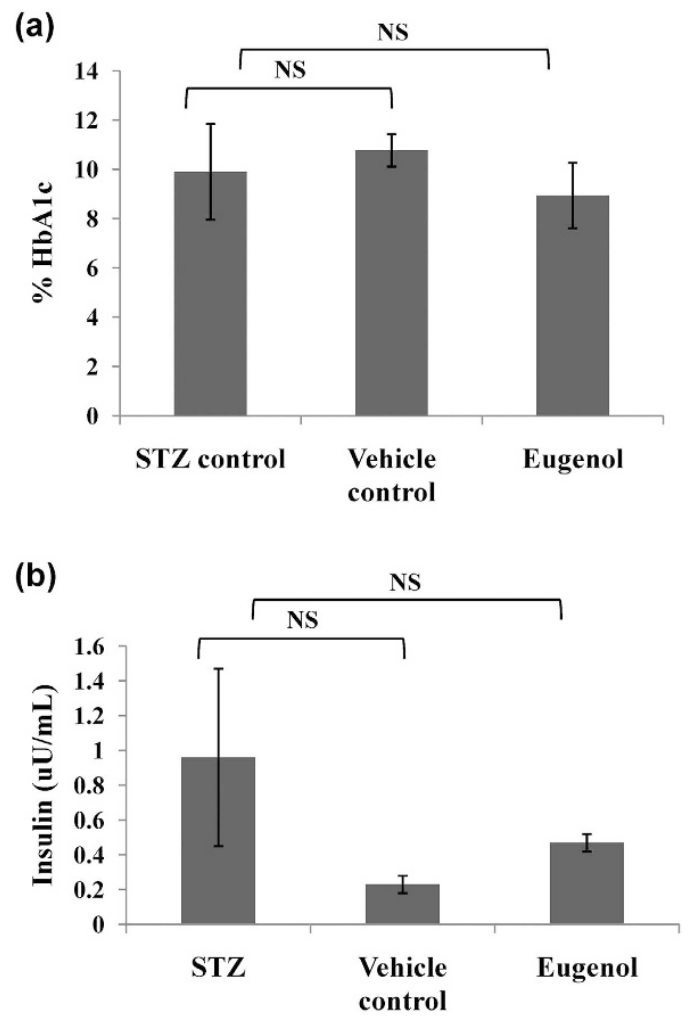

Figure 7. Analysis of blood biochemical parameters. Measurement of (a) HbAlc, (b) plasma insulin. Unpaired t-test suggested significant differences between data at $p<0.05$ (indicated as (*)). NS represents nonsignificant difference in data.

above observations were strongly supported by biophysical, biochemical, proteomic and histopathological studies. Thus, here we report eugenol, isolated from O. gratissimum, as a natural, FDA-approved non-toxic potent inhibitor of AGEs that can be used in management of diabetes.

\section{Materials and Method}

Chemicals and plant material. All chemicals were procured from Sigma-Aldrich (St Louis, MO, USA), otherwise mentioned. Yeast $\alpha$-glucosidase and $p$-nitrophenyl- $\alpha$-D-glucopyranoside were procured from SRL and Himedia (Mumbai, MS, India), respectively. Three species namely O. kilimandscharicum, O. tenuiflorum and O. gratissimum were grown under the following greenhouse conditions: temperature, 28 to $30^{\circ} \mathrm{C}$; humidity, 35 to $40 \%$; light conditions, $16 \mathrm{~h}$ light, $8 \mathrm{~h}$ dark. After harvesting, tissue was immediately subjected to further extraction procedure.

Gas chromatography-mass spectrometry (GC-MS) analysis of Ocimum plant tissues. Extractions were performed as described earlier ${ }^{25}$. Leaf tissue $(1 \mathrm{~g})$ was mixed in $10 \mathrm{~mL}$ dichloromethane (DCM) and kept for 18 to $24 \mathrm{~h}$ at $28^{\circ} \mathrm{C}$. The extract was filtered and incubated for $2 \mathrm{~h}$ at $-20^{\circ} \mathrm{C}$ to allow lipid precipitation. DCM extract was filtered again, concentrated under vacuum on a rotary evaporator and subjected to GC and GC-MS analyses as reported previously ${ }^{25}$.

Purification and NMR characterization of major metabolites from Ocimum species. Large-scale metabolite extraction was performed using $10 \mathrm{~g}$ leaves as mentioned earlier ${ }^{25}$. Thin-layer chromatography (TLC) was performed on silica gel G-coated plates $(0.25 \mathrm{~mm}$ for analytical $)$ developed three times in $5 \%$ petroleum ether in ethyl acetate. Compounds were visualized under UV light $(254 \mathrm{~nm})$ or by spraying with a solution of $3 \%$ anisaldehyde, $2.8 \% \mathrm{H}_{2} \mathrm{SO}_{4}, 2 \%$ acetic acid in ethanol followed by heating for 1 to $2 \mathrm{~min}$. Purification of major compounds was performed by flash chromatography using 240-400 mesh silica gel columns and petroleum ether-ethyl acetate gradient mixture as the eluent.

NMR $\left({ }^{1} \mathrm{H}\right.$ and $\left.{ }^{13} \mathrm{C}\right)$ for purified compounds was carried out on Bruker DRX-500 (500 MHz), Bruker AC-200 $(200 \mathrm{MHz})$ spectrometers in $\mathrm{CDCl}_{3}$. Chemical shifts were reported in parts per million, with respect to tetramethylsilane as the internal standard.

BSA-AGE fluorescence assay. Stock solutions $(100 \mathrm{mM})$ of aminoguanidine hydrochloride, ocimene, $\alpha$-pinene, terpinolene, farnesene, $\beta$-caryophyllene, camphor, eugenol, eugenol methyl ether (EME) and eucalyptol were prepared in $30 \% \mathrm{DMSO}$ and vortexed for $15 \mathrm{~min}$ for uniform mixing. For extract preparation, dichloromethane extract was concentrated to dryness under vacuum on a rotary evaporator, re-dissolved in $30 \%$ DMSO and vortexed for $15 \mathrm{~min}$. 
(a)

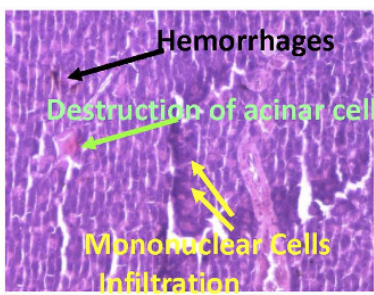

(b)

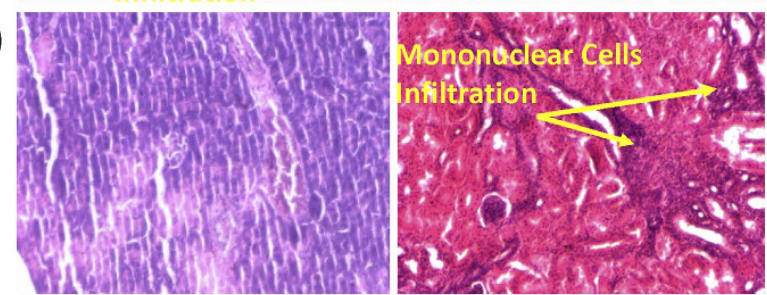

(c)

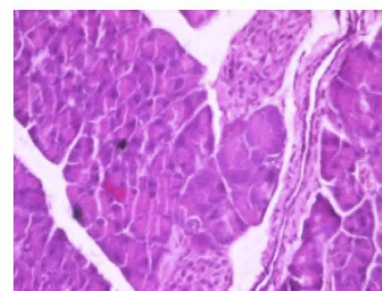

Pancreas
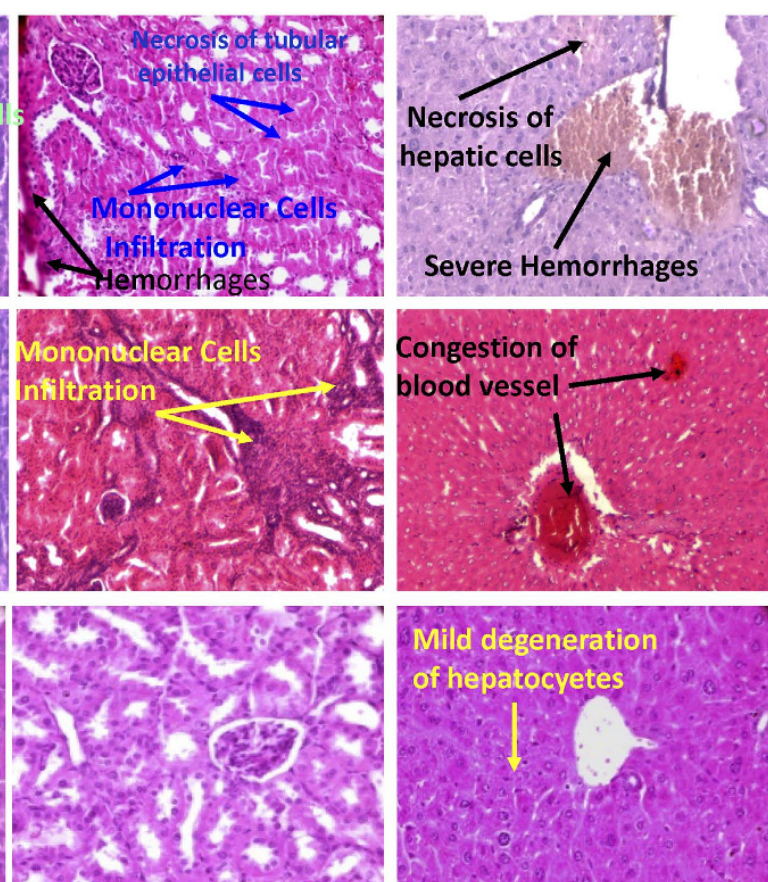

Kidney

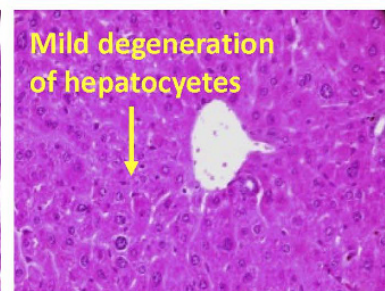

Liver
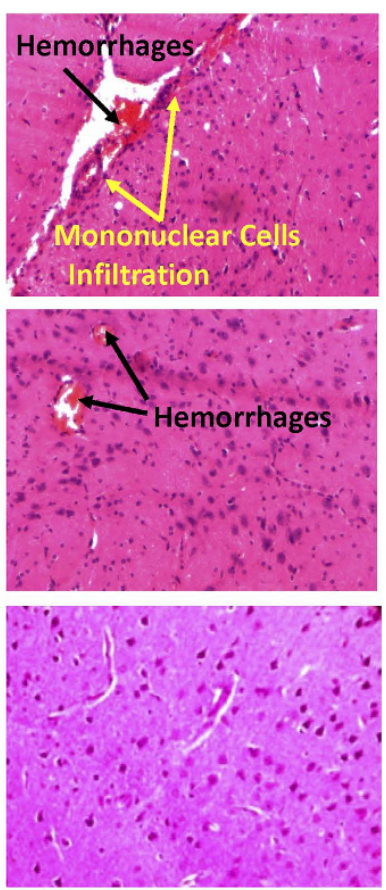

Brain

Figure 8. Histopathological examination of pancreas, kidney, liver and brain tissues of (a) STZ control (b) vehicle control (c) eugenol treated mice. Arrows indicate histopathological lesions in respective tissues.

(a)

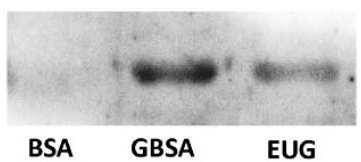

(c)

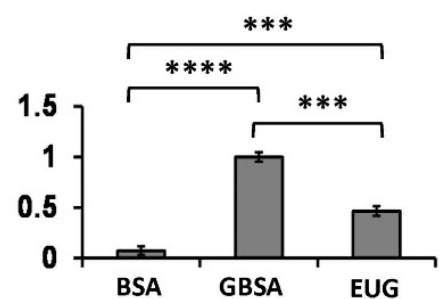

(b)

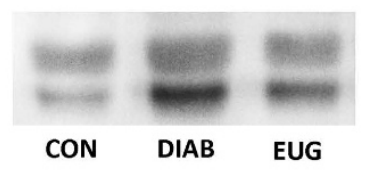

(d)

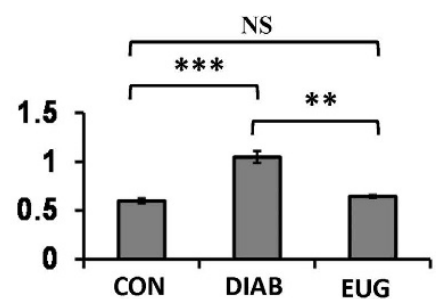

(f)

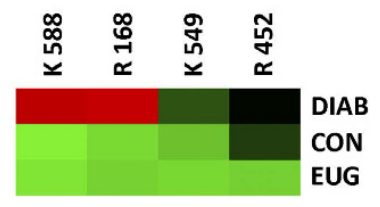

Figure 9. Proteomic analysis of in vitro and in vivo samples for AGE formation. Western blot using antiAGE antibody \& blot density analysis of in vitro BSA-AGE assay samples (a,c) and in vivo plasma samples (b,d) for probing AGE formation. One way ANOVA followed by unpaired t-test suggested significant differences between data at $p<0.01$ (indicated as (**'), $p<0.001$ (indicated as ${ }^{\left(* * x^{\prime}\right.}$ ) and $p<0.0001$ (indicated as ${ }^{\left(* * * x^{\prime}\right.}$ ). NS represents non-significant difference in data. Heat map showing extent of AGE induced modifications on specific lysine and arginine residues in (e) in vitro BSA-AGE assay and (f) plasma protein, identified by LC-MS ${ }^{\mathrm{E}}$. Heat map generated using Multi Experiment Viewer (MEV) software. (GBSA, glycated BSA; AMG, aminoguanidine; EUG, eugenol-treated sample; CON, control healthy mice; DIAB, STZ control plasma). 


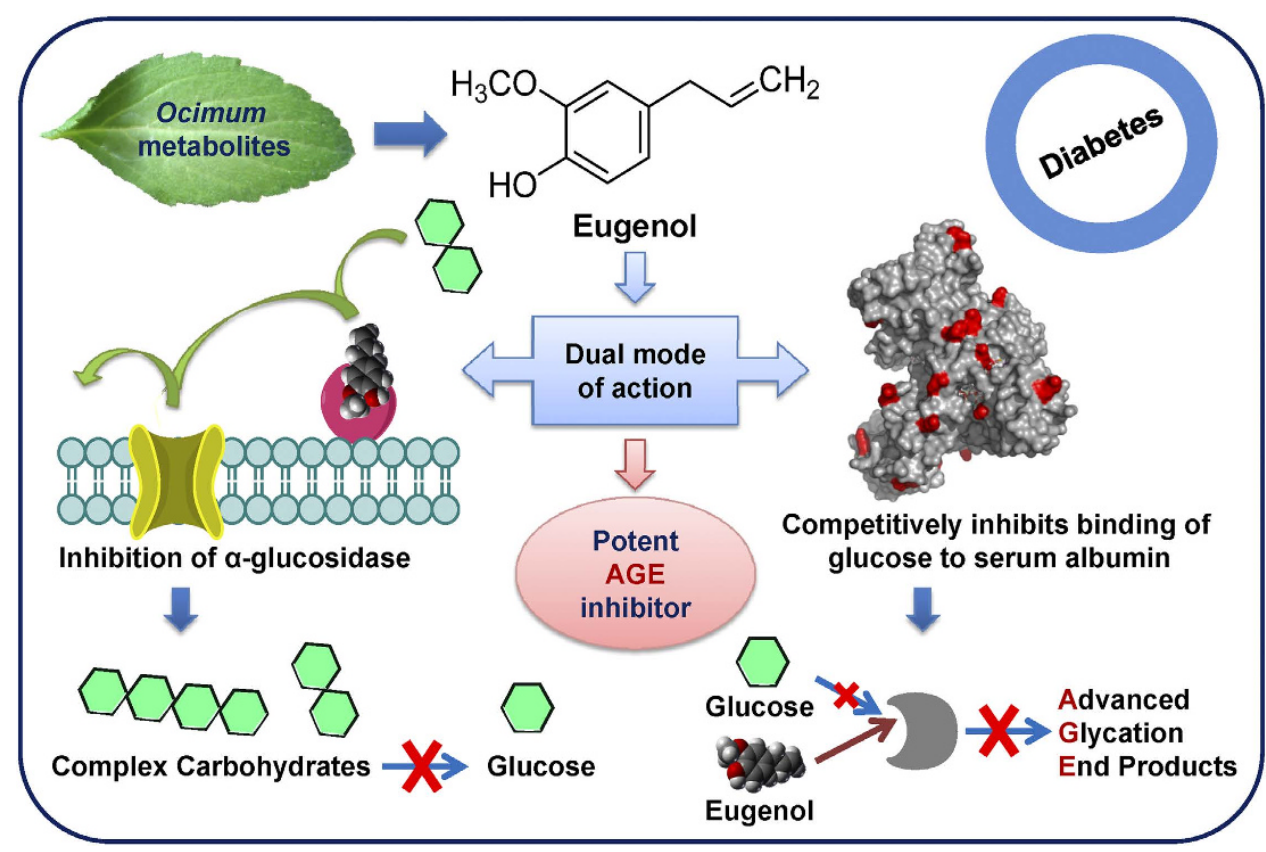

Figure 10. Schematic presentation of proposed potential dual role of eugenol in inhibiting AGEs. Leaf photograph courtesy, R.H.J. (co-author).

The reaction was set up as described earlier ${ }^{30}$. BSA glycation reaction was carried out by incubating $1 \mathrm{~mL}$ of $50 \mathrm{mg} \mathrm{mL}^{-1} \mathrm{BSA}$ in $0.1 \mathrm{M}$ phosphate buffer $(\mathrm{pH} 7.4)$ and $0.5 \mathrm{M}$ dextrose monohydrate containing $5 \mathrm{mM}$ sodium azide as bacteriostat at $37^{\circ} \mathrm{C}$ for 7 days with extracts and $15 \mathrm{mM}$ of above mentioned compounds. DMSO (30\%) and aminoguanidine were used as solvent and positive control, respectively. The BSA glycation was monitored at $370 / 440 \mathrm{~nm}$ by using Varioskan Flash 4.00 .53 spectrofluorometer (Thermo Scientific, Waltham, MA, USA). Percent inhibition of glycation was calculated by using the formulae; $(\mathrm{C}-\mathrm{T}) / \mathrm{C} \times 100$ where $\mathrm{C}$ is the relative fluorescence intensity of glycated BSA in absence of an inhibitor and $\mathrm{T}$ is the relative fluorescence intensity of glycated BSA in presence of an inhibitor.

Blind docking and probability analysis. Blind docking and probability analysis of eugenol with mouse serum albumin (MSA) was performed as described earlier ${ }^{31}$.

Intrinsic fluorescence assay. BSA $\left(50 \mathrm{mg} \mathrm{mL}^{-1}\right)$ in phosphate buffer $(50 \mathrm{mM}, \mathrm{pH} 7.4)$ was incubated at $37^{\circ} \mathrm{C}$ for $2 \mathrm{~h}$ with different concentrations of eugenol (1-50 mM) dissolved in $30 \%$ DMSO. Intrinsic fluorescence was monitored using spectrofluorometer (excitation: $280 \mathrm{~nm}$, emission: $300-450 \mathrm{~nm}$ ).

Circular dichorism analysis of BSA and BSA-eugenol complexes. BSA $\left(50 \mathrm{mg} \mathrm{mL}^{-1}\right)$ in phosphate buffer $(50 \mathrm{mM}, \mathrm{pH} 7.4)$ was incubated at $37^{\circ} \mathrm{C}$ for $2 \mathrm{~h}$ with varying concentrations of eugenol $(5,10$ and $25 \mathrm{mM})$ dissolved in $30 \%$ DMSO. $0.02 \mathrm{mg} \mathrm{mL}^{-1}$ concentration of protein was used to measure the CD spectra. All the $\mathrm{CD}$ spectra were recorded at room temperature $\left(24^{\circ} \mathrm{C}\right)$ using JASCO J-815 CD spectropolarimeter (Jasco Inc., Easton, MD, USA) over wavelength ranging from 250-190 nm.

Animal experiments. Ethics statement: All animal experiments were approved by Institutional Animal Ethics Committee of National Centre for Cell Sciences, Pune, MS, India. The experimental protocols were carried out in accordance with the guidelines of Committee for the Purpose of Control and Supervision of Experiments on Animals, India

Twenty healthy male balb/c mice, 6 to 8 weeks old, weighing 20 to $25 \mathrm{~g}$ were used for experiments. Mice were maintained in standard polyvinyl cages under the following conditions: temperature, 24 to $26^{\circ} \mathrm{C}$; humidity, 35 to $40 \%$; light conditions, $16 \mathrm{~h}$ light, $8 \mathrm{~h}$ dark and fed on pellet diet and water ad libitum. Streptozotocin (STZ; $45 \mathrm{mg} / \mathrm{kg}$ body weight, $100 \mu \mathrm{L}$ ) was administered intraperitoneally in citrate buffer $(50 \mathrm{mM}, \mathrm{pH} 4.5)$ to mice for 5 consecutive days to induce diabetes. Mice were monitored for a period of 15 days for establishment of stable hyperglycemic condition. During this time parameters like weight, water intake, physical appearance, animal behavior, urine output and blood glucose were measured routinely. Mice which displayed stable hyperglycemic condition were chosen for experiments and divided in three groups: Group I, STZ control; Group II, Vehicle control; Group III, eugenol- treated mice. 3 mice per control group and 9 mice per treated group were taken. $100 \mu \mathrm{L}$ intraperitoneal injection of eugenol $(100 \mathrm{mg} / \mathrm{kg}$ body weight) in vehicle (Ethanol: Tween80: Saline =1:1:18) twice a week for two weeks was administered. Time between consecutive injections was 3 days. 
Estimation of blood glucose and $\mathrm{HbA1c}$ levels. Blood glucose and $\mathrm{HbA1c}$ levels were measured using Bayer's CONTOUR blood glucose meter and Bayer A1C Now Kit (Bayer, Leverkusen, NRW, Germany), respectively according to the manufacturer's instructions.

$\alpha$-glucosidase inhibition assay and kinetics. $\alpha$-glucosidase inhibition assay was performed as described earlier ${ }^{32}$. $100 \mu \mathrm{L}$ eugenol in varying concentration (2.5 to $12.5 \mathrm{mM}$; prepared in $\left.30 \% \mathrm{DMSO}\right), 50 \mu \mathrm{L}$ of $5 \mathrm{mM} p$-nitrophenyl- $\alpha$-D-glucopyranoside (PNPG) and $50 \mu \mathrm{L}$ yeast $\alpha$-glucosidase $(0.25 \mathrm{U} / \mathrm{mL})$ were mixed and incubated at $37^{\circ} \mathrm{C}$ for $30 \mathrm{~min}$. Reaction was terminated by addition of $2 \mathrm{~mL}$ of $200 \mathrm{mM} \mathrm{Na} \mathrm{CO}_{3}$. Amount of $p$-nitrophenol released was measured using a spectrophotometer at $405 \mathrm{~nm}$. Mode of inhibition of yeast $\alpha$-glucosidase by eugenol was determined by measuring enzyme activity with increasing concentration of PNPG in the presence and absence of eugenol at different concentration ${ }^{32}$. Type of enzyme inhibition was determined using Lineweaver-burke plot analysis using Michelis-Menten kinetics.

Plasma collection and insulin measurement. Plasma was collected on the last day of experiment (day 45) and stored at $-80^{\circ} \mathrm{C}$ until further use. Plasma insulin measurements were performed at Department of Biochemistry, King Edward Memorial (KEM) Hospital, Pune, MS, India.

Tissue processing for histopathology. Mice were sacrificed on the last day of experiment (day 45) by cervical dislocation. Part of spleen, liver, heart, lungs, kidney, pancreas and brain were fixed in $10 \%$ formalin for histopathological analysis. Tissues were processed in a Leica TP 1020 tissue processor and embedded in paraffin blocks using Leica EG 1160 paraffin embedder. The paraffin blocks were cut into sections of $4 \mathrm{~mm}$ using a Microm HM 360 microtome. The slides were stained with hemotoxylin and eosin using a Microm HMS-70 stainer. Permanent slides were made and evaluated for histopathological changes under Olympus BX51 microscope.

Western blotting. Western blotting was performed in biological duplicates and technical triplicates for plasma samples. In vitro BSA-AGE assay was performed in duplicate and technical triplicates of each sample. Protein $(5 \mu \mathrm{g})$, in each case, was resolved on $12 \%$ SDS-PAGE, transferred onto polyvinylidene difluoride membrane (PVDF) membranes and blocked overnight at $4{ }^{\circ} \mathrm{C}$ with $5 \%$ membrane blocking agent prepared in TBS. The membranes were incubated with primary antibody Anti-AGE (Abcam) at a dilution of 1:2000 for 1 h, followed by 1:5000 secondary antibody (Goat Anti-Rabbit IgG) conjugated with horseradish peroxidase (HRP) for 30 min. Protein bands were visualized using WesternBright ECL HRP substrate (Advansta, Menlo Park, CA, USA) and documented by using Syngene DYVERSITY gel doc system (Syngene, Cambridge, UK).

In-gel trypsin digestion and LC-MS analysis of in vitro samples. In gel trypsin digestion was performed a described earlier ${ }^{33}$. Tryptic peptides were analyzed by nano LC-MS ${ }^{\mathrm{E}}$ (MS at elevated energy) using a Nano Acquity UPLC system (Waters Corporation, Milford, MA) online coupled to a Q-TOF, SYNAPT-HDMS (Waters Corporation) as described by Cheng et al. ${ }^{34} \mathrm{LC}-\mathrm{MS}^{\mathrm{E}}$ data were processed using Protein Lynx Global Server 2.4 (PLGS; Waters Corporation). Search was performed against UniProt-P02769 (BSA) sequence database. Glycation modifications of lysine, amadori $(+162.05 \mathrm{Da})$, CML $(+58.0 \mathrm{Da})$ and CEL $(+72.02 \mathrm{Da})$ were considered as additional variable modifications. Glycation modifications identified by PLGS were manually validated as described by Bhonsle et al. ${ }^{35,36}$

In-solution trypsin digestion and LC-MS/MS analysis of plasma proteins. In solution trypsin digestion was performed as described earlier ${ }^{33}$. Peptides were desalted using Zip tip C18 (Millipore, Billerica, MA, USA), concentrated by vacuum centrifuge and stored at $-20^{\circ} \mathrm{C}$ until further use. Peptides $(5 \mu l$ injections containing $3.5 \mu \mathrm{g}$ of peptides) were loaded on Eskigent C18 reverse phase column $\left(100^{\star} 0.3 \mathrm{~mm}, 3 \mu \mathrm{m}, 120 \AA\right.$ ) with $97 \%$ of mobile phase A ( $100 \%$ water, $0.1 \%$ formic acid) and $3 \%$ of mobile phase B ( $100 \%$ acetonitrile, $0.1 \%$ formic acid) at $8 \mu \mathrm{l} / \mathrm{min}$ flow rate. The peptides were separated at $8 \mu \mathrm{l} / \mathrm{min}$ flow rate for $100 \mathrm{~min}$ linear gradient of $3 \%$ to $50 \%$ mobile phase B. After $100 \mathrm{~min}$ the gradient was raised to $90 \% \mathrm{~B}$ for $9 \mathrm{~min}$ and the column was re-equilibrated to $3 \%$ mobile phase B for $11 \mathrm{~min}$. All samples were analyzed on Triple TOF 5600 mass spectrometer (Sciex; Concord, ON, Canada) as described by Jones et al. ${ }^{37}$ The samples were acquired in positive and high-sensitivity mode using Electrospray ionization (ESI) method. The acquired MS dataset was processed using the Proteome Discoverer software (Version 1.4.1.14, Thermo Fisher Scientific, Bremen, Germany). SEQUEST HT search engine was used for peptide identification. Data was searched against UniProt P07724 (mouse serum albumin) sequence database. Ion search parameters used included peptide precursor and fragment mass tolerance- $10 \mathrm{ppm}$ and $0.5 \mathrm{Da}$ respectively with 2 missed cleavages and 1\% FDR. Glycation modifications of lysine, Amadori (162.05 Da), CML $(+58.0 \mathrm{Da})$ and CEL $(+72.02 \mathrm{Da})$ were considered as additional variable modifications.

Statistical Analysis. GC-MS analyses of leaf tissue, in vitro BSA-AGE assay/s for extracts and compounds and $\mathrm{IC}_{50}$ assays for eugenol and aminoguanidine were performed in triplicates and values were represented as mean \pm standard deviation. Unpaired t-test was performed for blood glucose, plasma insulin and HbAlc measurements. Western blotting for plasma samples was performed in biological duplicates and technical triplicates. One-way ANOVA followed by unpaired t-test was performed for blot density analysis. Unpaired t-test suggested significant differences between data at $p<0.0001$ (indicated as (****'), $p<0.001$ (indicated as (***'), $p<0.01$ (indicated as ${ }^{(* *)}$ ) and $p<0.05$ (indicated as ${ }^{(*)}$ ). NS represents non-significant difference in data.

\section{References}

1. Van De Laar, F. A. et al. $\alpha$-Glucosidase inhibitors for patients with type 2 diabetes: results from a Cochrane systematic review and meta-analysis. Diabetes Care 28, 154-163 (2005)

2. Scheen, A. J. Clinical efficacy of acarbose in diabetes mellitus: a critical review of controlled trials. Diabetes Metab. 24, 311-320 (1998). 
3. Fukaya, N. et al. The alpha-glucosidase inhibitor miglitol delays the development of diabetes and dysfunctional insulin secretion in pancreatic beta-cells in OLETF rats. Eur. J. Pharmacol. 624, 51-57 (2009).

4. Matsumoto, K. et al. Effects of voglibose on glycemic excursions, insulin secretion, and insulin sensitivity in non-insulin-treated NIDDM patients. Diabetes Care 21, 256-260 (1998).

5. Brownlee, M. Advanced protein glycosylation in diabetes and aging. Annu. Rev. Med. 46, 223-234 (1995).

6. Brownlee, M. The pathobiology of diabetic complications. Diabetes 54, 1615-1625 (2005).

7. Luthra, M. \& Balasubramanian, D. Nonenzymic glycation alters protein structure and stability. J. Biol. Chem. 288, 18119-18127 (1993).

8. Kulkarni, M. J., Korwar, A. M., Mary, S., Bhonsle, H. S. \& Giri, A. P. Glycated proteome: From reaction to intervention. Proteomics Clin. Appl. 7, 155-170 (2013).

9. Vinson, J. A. \& Howard, T. B. Inhibition of protein glycation and advanced glycation end products by ascorbic acid and other vitamins and nutrients. J. Nutr. Biochem. 7, 659-663 (1996).

10. Urios, P., Grigorova-Borsos, A. M. \& Sternberg, M. Aspirin inhibits the formation of pentosidine, a cross-linking advanced glycation end product, in collagen. Diabetes Res. Clin. Pract. 77, 337-340 (2007).

11. Ruggiero-Lopez, D. et al. Reaction of metformin with dicarbonyl compounds. Possible implication in the inhibition of advanced glycation end product formation. Biochem. Pharmacol. 58, 1765-1773 (1999).

12. Kesavan, S. K. et al. Proteome wide reduction in AGE modification in streptozotocin induced diabetic mice by hydralazine mediated transglycation. Sci. Rep. 3, 2941 (2013).

13. Vasan, S. et al. An agent cleaving glucose derived protein crosslinks in vitro and in vivo. Nature 382, 275-278 (1996).

14. Mizutani, K., Ikeda, K. \& Yamori, Y. Resveratrol inhibits AGEs-induced proliferation and collagen synthesis activity in vascular smooth muscle cells from stroke-prone spontaneously hypertensive rats. Biochem. Biophys. Res. Commun. 274, 61-67 (2000).

15. Tang, Y. Curcumin eliminates the effect of advanced glycation end-products (AGEs) on the divergent regulation of gene expression of receptors of AGEs by interrupting leptin signaling. Lab. Invest. 94, 503-516 (2014).

16. Raskin, P. et al. Combination therapy for Type 2 diabetes: repaglinide plus rosiglitazone. Diabetic Med. 21, 329-335 (2004).

17. Matsumoto, K. et al. Combination therapy of alpha-glucosidase inhibitor and a sulfonylurea compound prolongs the duration of good glycemic control. Metabolism 51, 1548-1552 (2002).

18. Chiasson, J. L. \& Naditch, L. The synergistic effect of miglitol plus metformin combination therapy in the treatment of type 2 diabetes. Diabetes Care 24, 989-994 (2001).

19. Prakash, P. \& Gupta, N. Therapeutic uses of Ocimum sanctum Linn (Tulsi) with a note on eugenol and its pharmacological actions: a short review. Indian J. Physiol. Pharmacol. 49, 125-131 (2005).

20. Hakkim, F. L., Arivazhagan, G. \& Boopathy, R. Antioxidant property of selected Ocimum species and their secondary metabolite content. J. Med. Plants Res. 2, 250-257 (2008).

21. Bhargava, K. P. \& Singh. N. Anti-stress activity of Ocimum sanctum Linn. Indian J. Med. Res. 73, 443-451 (1981).

22. Karthikeyan, K., Gunasekaran, P., Ramamurthy, N. \& Govindasamy, S. Anticancer activity of Ocimum sanctum. Pharmac. Biol. 37, 285-290 (1999).

23. Uma Devi, P., Ganasoundari, A., Vrinda, B., Srinivasan, K. K. \& Unnikrishnan, M. K. Radiation protection by the Ocimum flavanoids orientin and vicenin: mechanisms of action. Radiat. Res. 154, 455-460 (2005).

24. Khan, A., Ahmad, A., Manzoor, N. \& Khan, L. A. Antifungal Activities of Ocimum sanctum essential oil and its lead molecules. Nat. Prod. Commun. 5, 345-349 (2010).

25. Singh, P. et al. Insecticidal Potential of Defense Metabolites from Ocimum kilimandscharicum against Helicoverpa armigera. PLoS ONE 9, e104377 (2014).

26. Chattopadhyay, R. R. Hypoglycemic effect of Ocimum sanctum leaf extract in normal and streptozotocin diabetic rats. Indian J. Exp. Biol. 31, 891-893 (1993).

27. Hannan, J. M. et al. Ocimum sanctum leaf extracts stimulate insulin secretion from perfusd pancreas, isolated islets and clonal pancreatic beta-cells. J. Endocrinol. 189, 127-136 (2006).

28. Bors, W. \& Michel, C. Chemistry of the antioxidant activity of polyphenols. Ann. N Y Acad. Sci. 957, 57-69 (2002).

29. Zhang, M., Xu, W. \& Deng, Y. A New Strategy for Early Diagnosis of Type 2 Diabetes Mellitus by standard- free, label- free LC- MS/ MS quantification of glycated peptides. Diabetes 62, 3936-3942 (2013).

30. Yanagisawa, K. et al. Specific fluorescence assay for advanced glycation end products in blood and urine of diabetic patients. Metabolism 47, 1348-1353 (1998)

31. Kolekar, Y. M. et al. Investigation of antiglycation activity of isoprenaline. RSC Adv. 5, 25051-25058 (2015).

32. Elya, B. et al. Screening of $\alpha$-glucosidase inhibitory activity from some plants of apocynaceae, clusiaceae, euphorbiaceae, and rubiaceae. J. Biomed. Biotechnol. 2012, 1-6, doi: 10.1155/2012/281078 (2011).

33. Bhonsle, H. S. et al. Low plasma albumin levels are associated with increased plasma protein glycation and HbAlc in diabetes. J. Proteome Res. 11, 1391-1396 (2012).

34. Cheng, F. Y., Blackburn, K., Lin, Y. M., Goshe, M. B. \& Williamson, J. D. Absolute protein quantification by LC/MS (E) for global analysis of salicylic acid-induced plant protein secretion responses. J. Proteome Res. 8, 82-93 (2009).

35. Bhonsle, H. S. et al. "Zoom-ln"-A targeted database search for identification of glycation modifications analyzed by untargeted tandem mass spectrometry. Eur. J. Mass Spectrom. 18, 475-481 (2012).

36. Korwar, A. M. et al. Development of diagnostic fragment ion library for glycated peptides of human serum albumin: Targeted quantification in prediabetic, diabetic and microalbuminuria plasma by parallel reaction monitoring, SWATH and MSE. Mol. Cell Proteomics 14, 2150-2159 (2015).

37. Jones, K. A. et al. Immunodepletion plasma proteomics by tripleTOF 5600 and Orbitrap elite/LTQ-Orbitrap Velos/Q exactive mass spectrometers. J. Proteome Res. 12, 4351-4365 (2013).

\section{Acknowledgements}

P.S. and A.A. acknowledge support from Council of Scientific and Industrial Research (CSIR), New Delhi for research fellowships. This research work is supported by CSIR under XII five-year plan network project (BSC0124). We thank Dr. P.R. Rajamohanan (CSIR-NCL, Pune) and his team for help in NMR analysis.

\section{Author Contributions}

P.S., A.P.G., M.J.K., T.H.V. and R.B. conceived and designed the experiments. P.S., A.P.G., A.M.K., G.V., R.H.J. and T.H.V. analyzed the data. P.S., S.B.A., M.L.S. and V.S.D. performed the animal experiments and R.B. supervised animal experiments. R.H.J. and A.A. did chemical profiling. R.S.J. carried out in silico analysis and interpreted data. P.S., A.M.K., A.P.G. and M.J.K. wrote the manuscript. All authors reviewed the whole work, and edited and approved the manuscript.

Additional Information

Supplementary information accompanies this paper at http://www.nature.com/srep 
Competing financial interests: The authors declare no competing financial interests.

How to cite this article: Singh, P. et al. Potential Dual Role of Eugenol in Inhibiting Advanced Glycation End Products in Diabetes: Proteomic and Mechanistic Insights. Sci. Rep. 6, 18798; doi: 10.1038/srep18798 (2016).

(c) (i) This work is licensed under a Creative Commons Attribution 4.0 International License. The images or other third party material in this article are included in the article's Creative Commons license, unless indicated otherwise in the credit line; if the material is not included under the Creative Commons license, users will need to obtain permission from the license holder to reproduce the material. To view a copy of this license, visit http://creativecommons.org/licenses/by/4.0/ 